DOI: $10.17805 /$ trudy.2019.3.6

\title{
РОЛЬ ЯЗЫКА И ТРАДИЦИОННОГО ИСКУССТВА В ПОСТИЖЕНИИ СПЕЦИФИКИ ДЕЛОВОЙ КУЛЬТУРЫ ВОСТОКА (НА ПРИМЕРЕ ЯПОНИИ)
}

\author{
Г. А. Гвоздевская \\ Московский гуманитарный университет
}

\begin{abstract}
Аннотация: В статье представлен авторский методологический подход к формированию межкультурной компетенции, в основу которого положена идея прочувствования закономерностей мировосприятия, свойственных Востоку, в процессе комплексного постижения традиционного искусства, языка и специфики деловой культуры региона (на примере Японии).

Ключевые слова: японская традиционное искусство; японский язык; деловая культура; миропонимание; Япония

\section{THE ROLE OF LANGUAGE AND TRADITIONAL ART IN UNDERSTANDING THE SPECIFICS OF THE BUSINESS CULTURE OF THE EAST (EXEMPLIFIED BY JAPAN)}

\author{
G. A. Gvozdevskaya \\ Moscow University for the Humanities
}

Abstract: The article presents the author's methodological approach to the formation of intercultural competence, which is based on the idea of perceiving the patterns of world perception peculiar to the East, in the process of comprehensive understanding the traditional art, language and specifics of the region's business culture (using Japan as an example).

Keywords: Japanese traditional art; Japanese language; business culture; world outlook; Japan

В современном глобализирующемся мире неизбежно встают проблемы межкультурного взаимодействия, среди которых одна из наиболее трудных - диалог Запада и Востока. С поиском путей ее решения, как известно, связано появление в середине XX века такой науки, как межкультурная коммуникация, которая стала изучаться как учебная дисциплина в зарубежных и отечественных вузах. С ней связано формирование особого направления в теории и практике бизнеса - кросс-культурного менеджмента. В исследованиях классиков межкультурной коммуникации (Льюис, 2001; Trompenaars, Hampden-Turner, 1997; Hall, 1976; Hall, E., Hall, M. 1990; Hofstede, 2010) представлены модели деловых культур на основе выделения параметров различий по отношению к природе, восприятию времени, организации пространства, установленным в социуме правилам, стилю коммуникации, принятию решений и т. д. В отдельных исследованиях вводятся специфические понятия, характеризующие восточную деловую культуру («принцип конфу- 
Научные труды Московского гуманитарного университета 2019 № 3

цианского динамизма» у Г. Хофстеде, понятие «реактивной культуры» у Р. Льюиса). В качестве практических методов формирования межкультурной компетенции выступают преимущественно тренинги, основанные на теоретических постулатах науки и параметрах выше обозначенных моделей.

В настоящей статье предлагается авторский методологический подход к формированию данной компетенции, в основу которого положена идея прочувствования закономерностей мировосприятия, свойственных Востоку, в процессе комплексного постижения традиционного искусства, языка и специфики деловой культуры региона (на примере Японии). В отечественной лингвистике выделение культурологической составляющей в освоении языка является приоритетной областью современных исследований (Долгина, 2016; Исмаилова, 2016; Фатхулина, 2016). В силу полярности моделей миропонимания Запада и Востока мы считаем, что межличностное, деловое общение с представителями данных традиций, так же, как и путь к адекватному пониманию восточной культуры в целом, должны начинаться с психологической перестройки мировосприятия на волну остановки мгновения, своеобразного «недеяния», со-настроенности kokoro («сердце, дух, душа»). Тогда, например, в деловой коммуникации с японцами будет казаться естественным некатегоричность общения, использование характерных контекстуальных этикетных фраз, эмоциональная сдержанность, ограниченность жестикуляции, отсутствие суетливых движений, долгий путь принятия решений согласно концепции nemawashi («вращение вокруг корня») и т. д.

В предлагаемом подходе акцентируется внимание на обращении к восточному традиционному искусству как доминанты формирования представлений о созерцательно-цикличном отношении к течению времени, бесконфликтности, ощущению глубинной связи с природой и других констант метафизики Бытия на интуитивном уровне. Данная установка согласуется с изначальным восточным принципом познания мира, отличительной чертой которого является отсутствие свойственной западному мышлению дихотомии рационального и иррационального.

В свою очередь, национальный язык отражает в себе комплекс самобытных представлений о мире, являясь зеркалом мышления. Погружение в языковую среду - это вторая закономерная составляющая нашего подхода. Практическая реализация данного подхода, как мы полагаем, может иметь место на всех ступенях общего и профессионального образования (начиная от школы, заканчивая вузом) в преподавании различных дисциплин (в частности, культурологии, иностранного языка, практикума по межкультурной коммуникации, кросс-культурного менеджмента и многих других). В настоящий момент апробация данного подхода осуществляется в курсе «Практикум по межкультурной коммуникации», который ведет автор настоящей статьи в Московском гуманитарном университете. Далее будут представлены содержательные практические рекомендации в русле предлагаемого подхода на примере японской культуры. 
Приведем пример организации тренинга делового общения, рассчитанный на аудиторию, не владеющую японским языком. Его содержательную основу составляет идея психологической перестройки на специфику миропонимания, представленного в японской философии и культуре. Предлагается начать с освоения канона деловой переписки, связанного с концепцией 自然感 shizenkan, 季節感kisetsukan (ощущения связи с природой, изменениями сезонов). То, что обычно вызывает недоумение и внутреннее противоречие у европейцев в японском деловом письме - сезонные приветствия, многочисленные этикетные фразы, зачастую занимающие большее пространство, чем деловая часть, будет воспринято теперь гармонично по аналогии с музыкальной композицией, где важно состояние со-настроенности с окружающим, изначальная метафизика «недеяния».

Приведем примеры фрагментов личных писем с характерным сезонным приветствием - необходимым атрибутом учтиво-вежливого стиля в японской традиции:「春暖の候ますますお元気でご活躍のこととお慶び申 し上げます。」《В теплый весенний день пишу Вам, чтобы выразить свою радость по поводу того, что Вы здоровы и продолжаете плодотворно работать» (Фролова, 2012: 75); 「葉桜の季節となり、うららかな今日のころです が、いかがお過ごしでしょうか。」《Деревья сакуры покрылись листвой, стоит прекрасная погода, как Вы поживаете?» (Фролова, 2012: 109); 「新緑 の候、皆椂にはますますご清祥のこととお喜び申し上げます。」《Пишу к Вам в сезон молодой листвы. Мы рады, что у Вас все здоровы и все хорошо» (Фролова, 2012: 109); 「すっかク秋らしく参りました。先生にはお元気で お過ごすのことと存じます。」 《Вот уже совсем наступила осень. Надеюсь, что Вы здоровы» (Фролова, 2012: 138). Приведем пример делового письма, которое по традиции начинается с сезонного приветствия и этикетных клише 一 пожеланий фирме-партнеру:「帱啓 立春の候記者にますますご 盛栄の事とお喜び申し上げます。」《Милостивый государь! По случаю приближения весны позвольте пожелать все большего процветания и успехов Вашей фирме. Сообщаем, что недавно в нашей фирме был разработан новый товар ...» (Быкова, Мидори, Ямада, 2003: 79).

В качестве одного из вариантов тренинга комплексного освоения традиционного искусства, языка и деловой культуры Японии предлагается следующий алгоритм:

1. Разучивание некоторых клише деловой переписки на японском и русском языках.

2. Рисование иероглифов времен года (春haru — весна, 夏 natsu - лето, 秋aki - осень, 冬fuyu - зима) черной тушью по канонам японской каллиграфической традиции, где основной принцип - tomare - остановки движения, сохранение внутреннего состояния покоя. Предполагается рисование иероглифов, сопровождаемое звучанием композиций для традиционных японских инструментов (например, бамбуковой флейты shakuhachi, 13-струнной цитры koto, сочинений японских композиторов 20-21 веков 
Научные труды Московского гуманитарного университета

2019 № 3

(Miyagi Michio, Takemidzu Toro, Savai Tadao, Yokoyama Katsuya и др.), основанных на статике пребывания в одном созерцательном состоянии, в котором эмоциональные движения остановлены, индивидуальное «я» растворено в окружающем природном и трансцендентном пространстве).

3. Знакомство с проявлением выше обозначенного принципа «tomare» в искусстве 茶道sado - чайной церемонии, традиционном театре 能no:

4. Освоение «ритуального типа коммуникации» (термин Р. Льюиса) при обмене визитными карточками (речевых клише, жестов с характерной остановкой движения, системы поклонов, хранящих идею смирения «эго»).

С точки отсчета прочувствования через различные виды традиционных искусств констант мировосприятия, на которых базируется японская культура в целом и деловая, в частности, как закономерная ее составляющая, тренинги вербальной деловой коммуникации также могут обретать более глубинный содержательный смысл. Например, освоив несколько приветственных фраз на японском языке, можно провести тренинг обмена визитными карточками, достигая мягкой учтиво-вежливой интонации, гармоничной жестикуляции, поклонов, имеющих строго выверенную траекторию, при главном условии - сохранении состояния, где основа движения - покой.

Предложенный в настоящей статье комплексный подход к постижению японского традиционного искусства, языка и деловой культуры открывает новые перспективы в методах преподавания различных дисциплин, возвращаясь к первоистоку восточного синкретического мышления, основанного на метафизике созерцательного восприятия окружающего мира.

\section{СПИСОК ЛИТЕРАТУРЫ}

Быкова, С. А., Мидори, Ямада (2003) Японский язык. Пособие по переводу документации, М.: Муравей. 138 с.

Долгина, Н. А. (2016) Коммуникативные модели на деловых встречах как аспект при изучении дисциплины «Основы устной деловой коммуникации» // Высшее образование для XXI века. XIII международная научная конференция: доклады и материалы. М.: Изд-во Моск. гуманит. ун-та. С. 11-17.

Исмаилова, М. Ю. (2016) Театрализация как метод и средство формирования общекультурной компетенции обучающегося в процессе изучения английского языка // Высшее образование для XXI века. XIII международная научная конференция: доклады и материалы. М.: Изд-во Моск. гуманит. ун-та. С. 36-41.

Льюис, Р. Д. (2001) Деловые культуры в международном бизнесе. От столкновения к взаимопониманию. 2-е изд. / пер. с англ. М.: Дело. 448 с.

Фатхулина, Г. Г. (2016) Разработка технологического уровня дисциплины «Литература и иностранный язык» для обучения магистров гуманитарного вуза // Высшее образование для XXI века. XIII международная научная конференция: доклады и материалы. М.: Изд-во Моск. гум. ун-та. С. 74-78. 
Фролова, Е. Л. (2012) Личная и деловая переписка на японском языке. Учебно-методический комплекс / сост. Е. Л. Фролова. Новосибирск: Из-во Новосибирского ун-та. 162 с.

Hall, E. T. (1976) Beyond Culture / Hall, E. T. Anchor Books Editions. New York, London, Toronto, Sydney, Auckland. 320 p.

Hall, E. T., Hall, M. (1990) The Hidden Dimension. New York : Doubleday Anchor books, 2nd edition. 265 p.

Hofstede, G. (2010) Cultures and Organizations: Software of the Mind. Administrative Science Quarterly. London: McGraw-Hill, 3nd edition. 274 p.

Trompenaars, F., Hampden-Turner, Ch. (1997) Riding the Waves of Culture: Understanding Diversity in Global Business. London: Nicholas Brealey Publishing, 2nd edition. 265 p.

Дата поступления: 30.05.2019 2.

Гвоздевская Галина Анатольевна - кандидат педагогических наук, профессор кафедры иностранных языков и лингвистики Московского гуманитарного университета. Адрес: 111395, Россия, г. Москва, ул. Юности, д. 5. Тел.: +7 (499) 374-75-95. Эл. адрес: inyazling@mail.ru

Gvozdevskaya Galina Anatolyevna, Candidate of Pedagogy, Professor, Department of Foreign Languages and Linguistics, Moscow University for the Humanities. Postal address: 5, Yunosti St., Moscow, Russian Federation, 111395. Tel.: +7 (499) 374-75-95. E-mail: inyazling@mail.ru

\section{Для цитирования:}

Гвоздевская Г. А. Роль языка и традиционного искусства в постижении специфики деловой культуры Востока (на примере Японии) [Электронный ресурс] // Научные труды Московского гуманитарного университета. 2019. № 3. URL: http://journals.mosgu.ru/ trudy/article/view/995 (дата обращения: дд.мм.гг.). DOI: 10.17805/trudy.2019.3.6 